\title{
A EVOLUÇÃO DA MOLÉCULA DE VITAMINA A UTILIZADA EM FORMULAÇÕES COSMECÊUTICAS
}

\author{
Camila de Lima Oliveira ${ }^{3}$; Camila dos Santos Ferro 3 ; Karina Longati3; \\ Sthefannie Victoria Santos da Cunha3; Tairine Honda3; Valéria Maria de Souza Antunes'; \\ Carlos Rocha Oliveira².
}

1Docente do curso de Farmácia da Universidade Anhembi Morumbi e orientadora. ${ }^{2}$ Docente do curso de Farmácia da Universidade Anhembi Morumbi e co-orientador. ${ }^{3}$ Discentes do curso de Farmácia da Universidade Anhembi Morumbi e orientandas. E-mail para contato: valeriabelaclara@gmail.com.

\section{Resumo}

As vitaminas são indispensáveis em diversos processos biológicos, tornando-se crucial para o funcionamento do organismo humano. Devido seu potencial, diversas vitaminas são utilizadas para o desenvolvimento de cosmecêuticos. A Vitamina A foi o primeiro retinoide a ser estudado na área clínica, por sua importância na queretinização e diferenciação epitelial. Esta Revisão de Literatura tem o intuito de avaliar o aperfeiçoamento da molécula de vitamina A nos últimos 30 anos e a aplicação deste componente em formulações cosmecêuticas. Atualmente, os retinoides são uma das classes mais prescritas em dermatologia para preparações cosmeceuticas. São substâncias derivadas da Vitamina A, que de acordo com a literatura, possuem ação principalmente no tratamento de envelhecimento cutâneo, acne e fotoenvelhecimento. Observou-se uma série de inconvenientes associados a utilização de retinoides, como a instabilidade da molécula, os efeitos colaterais e o grande potencial teratogênico, dando início às pesquisas com objetivo de obtenção de um composto menos tóxico e com menores reações adversas. $\mathrm{O}$ primeiro composto utilizado foi o retinol, a forma ácida da Vitamina A, porém, um grande número de retinoides foram sintetizados ao longo dos anos, podendo ser caracterizados como de primeira, segunda e terceira geração. A mais recente molécula desenvolvida foi o retinoato de hidroxipinacolona, que apresenta menor irritação da pele, menor instabilidade fotoquímica e toxicidade. Contudo, apesar dos avanços, os retinoides continuam foto instáveis, com potencial teratogênico e irritativo para a pele, não sendo, portanto, substâncias totalmente seguras para o uso.

Palavras chave: Vitamina A, Retinoides, Retinoides Tópicos, Cosmecêuticos, Ativos dermatológicos.

Os produtos de uso tópico usualmente são categorizados em medicamentos e cosméticos, onde os primeiros possuem finalidade de aliviar, prevenir ou tratar doenças, além de possuírem inúmeras normativas que regulamentam a comprovação de segurança e eficácia, prévias ao registro e comercialização, já os segundos caracterizam-se como produtos destinados ao embelezamento e melhoria da aparência (COSTA, 2012; BARROS e ZAENGLEIN, 2017). Atualmente, atribui-se a alguns produtos cosméticos atividades que vão além de embelezar e manter as boas condições da pele, sendo estes chamados de 'cosmecêuticos' (CAETANO, 2012).

O termo 'cosmecêuticos' foi utilizado pela primeira vez em 1984 pelo dermatologista americano Albert Kligman (MANELA-AZULAY e BAGATIN, 2009; COSTA, 2012; BARROS e ZAENGLEIN, 2017) e provém da junção dos termos 'cosméticos' e 'farmacêuticos', que em suma são produtos que estariam em uma linha tênue entre cosméticos e fármacos, levando talvez a se pensar 


\section{Brazilian Journal of Natural Sciences | Versão On-line ISSN 2595 - 0584 \\ Edição no 1- vol. 1 - março 2018 | www.bjns.com.br}

que se trata de um cosmético pouco inerte ou um fármaco com pouca ação (COSTA, 2012; BARROS e ZAENGLEIN, 2017). No Brasil, o órgão responsável pela regularização dos produtos cosméticos, a Agência Nacional de Vigilância Sanitária (ANVISA), não reconhece o termo, e de acordo com sua norma regulamentadora vigente, $\mathrm{RDC} \mathrm{n}^{\circ} 7$, de 10 fevereiro de 2015 , os produtos cosméticos só podem ser classificados em grau 1 e grau 2 , sendo os cosmecêuticos melhor encaixados nas preparações cosméticas de grau 2, descritas como as que possuem atividade específica (BRASIL, 2015). De forma complementar, um cosmecêutico pode ser classificado como um produto de uso tópico, que ao interagir com a pele, pode levar a mudanças estruturais e/ou funcionais deste órgão, sem a atividade propriamente terapêutica de um fármaco, mas com a possibilidade preventiva, não sendo seu uso exclusivo ao embelezamento, como seria de uma maquiagem (COSTA, 2012; BARROS e ZAENGLEIN, 2017).

Compreendendo que os cosmecêuticos são cosméticos que contêm substâncias com potencial de alterar a função biológica da pele, sabe-se que inúmeros princípios ativos podem se tornar ingredientes nas mais variadas formulações, dentre eles as vitaminas (MANELA-AZULAY e BAGATIN, 2009; OBLONG e JARROLD, 2016).

As vitaminas são substâncias orgânicas que atuam como cofatores de muitos processos biológicos, sendo indispensáveis para o funcionamento do organismo humano. Entre as vitaminas utilizadas para o desenvolvimento de cosmecêuticos podemos destacar a vitamina $\mathrm{A}$, conhecida também pela sua forma natural alcoólica, o retinol (FAVARO DE ARRUDA, ARRUDA, et al., 2012).

A vitamina A (retinol) e seus derivados naturais conhecidos como retinoides são necessários para muitos processos biológicos, incluindo a visão, a reprodução, a morfogênese, a regulação das células epidérmicas, a diferenciação e a manutenção celular. Sendo a pele e os olhos os principais locais para os efeitos dependentes de retinoides (OBLONG e JARROLD, 2016).

Trata-se de um composto não sintetizado endogenamente, que pode ser obtido através da in- gestão de alimentos de origem animal na forma de retinóis, ou ainda a partir da metabolização de carotenoides, que são pigmentos naturais encontrados nos alimentos de origem vegetal, com grande variação estrutural e funções fisiológicas, sendo o carotenoide mais conhecido o $\beta$-caroteno (OBLONG e JARROLD, 2016).

Durante a metabolização do retinol, muitas formas intermediárias de retinoides são formadas, dentre elas, destacam-se os retinaldeídos e os ésteres de retinil, sendo os últimos, moléculas de depósito, armazenadas no fígado (OBLONG e JARROLD, 2016).

A classificação dos retinoides é dada pelo grupo terminal polar das moléculas: a presença de uma hidroxila origina um retinol; um aldeído origina retinal; um ácido carboxílico origina um ácido retinoico e um éster origina éster de retinil. Inicialmente eram considerados retinoides apenas compostos cuja estrutura e ação assemelhavam-se ao composto de origem, a vitamina A, da qual a molécula permite modificações através de substituições em seus grupos carboxílico final, na cadeia de poliênica ou no anel aromático, permitindo o desenvolvimento de produtos sintéticos. Logo, com o tempo, o termo retinoides foi ampliado, sendo utilizado também para se referir a estes compostos sintéticos com estrutura molecular semelhantes à vitamina A (KLIGMAN, 1998).

Atualmente os retinoides são classificados em três gerações. A primeira composta por retinoides não aromáticos, a segunda por retinoides mono-aromáticos, a terceira por retinoides poli-aromáticos (OBLONG e JARROLD, 2016).

Os retinoides podem, então, ser classificados como uma classe de substâncias que compreendem a vitamina A e seus compostos naturais e sintéticos (BARROS e ZAENGLEIN, 2017). São moléculas de caráter lipofílico, podendo se difundir através da membrana fosfolipídica celular e dentro das células, ligam-se a várias isoformas dos receptores nucleares do ácido retinoico e modificam a expressão de genes. Pelas características supracitadas, trata-se de um grupo de substâncias com possibilidade de uso como medicamentos e cosmecêuticos, a obedecer a concentração da 


\section{Brazilian Journal of Natural Sciences | Versão On-line ISSN 2595 - 0584 \\ Edição no 1- vol. 1 - março 2018 | www.bjns.com.br}

substância no produto, a formulação e o veículo no qual o retinoide foi dispersado (SORG, KUENZLI, et al., 2005).

Entendendo que os produtos cosmecêuticos podem ser classificados como naturais ou derivados sintéticos e que podem ser comprados sem a necessidade de receita médica, são elegíveis neste grupo os retinoides: ésteres de retinil, retinol e retinaldeído (SORG, ANTILLE, et al., 2006; BARROS e ZAENGLEIN, 2017). Para as formulações que utilizam retinoides como: tretinoina, alitretinoina, tazaroteno e adapaleno, dá-se à classificação de medicamento de uso tópico (BARROS e ZAENGLEIN, 2017), mas a título de estudo da evolução da molécula, estas moléculas também estarão nesta revisão.

\section{Da descoberta dos retinoides ao uso em cosme- cêuticos}

Os primeiros estudos envolvendo a vitamina $\mathrm{A}$ foram realizados por McCollum entre 1907 e 1913, e avaliavam inicialmente a relação do nutriente extraído da gema de ovo, com o crescimento e desenvolvimento de ratos, tal nutriente foi nomeado temporariamente de 'fator A solúvel em gordura', passados mais de vinte anos, já na década de 1930, Karrer et al. conseguiram determinar a estrutura química deste composto, agora denominado retinol, que foi totalmente sintetizado laboratorialmente em 1947 por Isler e Huber, tornando possível a produção industrial (KHALIL, BARDAWIL, et al., 2017).

A vitamina A é uma molécula hidrofóbica composta por três domínios estruturais: um anel cíclico; uma cadeia lateral poliênica; e um grupo terminal polar. Os retinoides são derivados da molécula de vitamina $A$, que apresentam substituintes em todos os três domínios estruturais (KHALIL, BARDAWIL, et al., 2017). Os retinoides naturais são constituídos por seis átomos de carbono, um anel não aromático e uma cadeia lateral poliprenoide, geralmente terminada com grupos funcionais compostos de carbono e oxigênio. Durante o processo de metabolismo desses retinoides ocorre o rearranjo estrutural, fazendo com que vários análogos ou moléculas intermediárias com efeitos biológicos potencialmente diversos ocorram (DINIZ, LIMA e ANTONIOSI FILHO, 2002).

No campo da dermatologia a importância dos retinoides e sua influência sobre a queratinização da pele de animais, foi apresentada inicialmente por Wolbach e Howe, o que culminou em posteriores estudos e achados voltados para avaliar essencialmente a atividade biológica dos retinoides na pele e, também, na utilização dessas substâncias como agentes terapêuticos (DINIZ, LIMA e ANTONIOSI FILHO, 2002).

$\mathrm{Na}$ pele, os retinoides regulam as funções de crescimento e diferenciação epidérmica, exercendo biologicamente seus efeitos a partir da ligação com receptores nucleares específicos, denominados RAR (retinoic acid receptors) e RXR (retinoid $\mathrm{X}$ receptors). Esse mecanismo foi descrito a primeira vez em 1987, onde os receptores para o ácido retinoico intracelulares, atuam como fatores de transcrição que são ativados tanto por isômeros, como por metabólitos do ácido retinoico (DINIZ, LIMA e ANTONIOSI FILHO, 2002).

As famílias de receptores retinoides são compostas cada uma por três subtipos $(\alpha, \beta, \gamma)$, formando homo ou heterodímeros que se ligam ao elemento responsivo do DNA e induzem a expressão ou downregulation de genes alvo. Os subtipos de receptores mais distribuídos na pele são RAR $\gamma$ e RXRa, e a formação de heterodímero por ambos, transduz os efeitos retinoides na pele humana (KHALIL, BARDAWIL, et al., 2017). Com o descobrimento dos RARs nucleares, novos agonistas sintéticos mais seletivos e fisiocoquimicamente melhorados, puderam ser desenvolvidos, tendo como alvo diferentes receptores.

Os retinoides influenciam na proliferação e diferenciação celular, especialmente dos epitélios queratinizantes, modificam também reações imunes, exercendo efeitos sobre processos inflamatórios, além de diminuir a atividade de glândulas sebáceas (FERNÁNDEZ e ARMARIO, 2003). O espectro de ação dos retinoides demonstram uma diferença considerável quando avaliamos a atividade biológica desencadeada, tal característica é essencial para determinar sua possível aplicação 


\section{Brazilian Journal of Natural Sciences | Versão On-line ISSN 2595 - 0584 \\ Edição no 1- vol. 1 - março 2018 | www.bjns.com.br}

clínica (DINIZ, LIMA e ANTONIOSI FILHO, 2002).

$\mathrm{Na}$ área clínica, o primeiro retinoide a ser estudado e utilizado foi a vitamina A, visto sua importância na diferenciação epitelial e queratinização, para o tratamento de distúrbios e queratinização, contudo, logo foi reconhecido uma proporção desfavorável entre os efeitos clínicos e colaterais, já que as doses usuais levavam geralmente a uma hipervitaminose, que se manifestava com alterações na epitelização cutânea e mucosa, além de sinais de comprometimento neurológico e hepático (KHALIL, BARDAWIL, et al., 2017).

A busca por derivados menos tóxicos levou a síntese da tretinoina, que foi posteriormente recomentada para o uso tópico, visto não ter evidenciado grandes vantagens para o uso sistêmico em relação a vitamina $A$, o que foi resolvido com a utilização de seu isômero isotretinoina, excelente para o tratamento da acne nodular (KHALIL, BARDAWIL, et al., 2017).

Contudo, o conceito de produto cosmecêutico de que não é um fármaco, mas que exerce atividade biológica demonstrável sem induzir graves efeitos colaterais, impede que se utilize os derivados diretos do ácido retinoico em preparações de venda livre, já que um dos efeitos mais comuns atribuídos ao uso desses compostos é o aparecimento de eritema, prurido, descamação e ressecamento da pele. Além disso, destaca-se como inconveniente os grandes cuidados relacionados a manipulação e armazenamento desses retinoides, dada sua instabilidade química (SORG, ANTILLE, et al., 2006).

Frente a este fato, várias modificações foram realizadas na molécula de vitamina $\mathrm{A}$, dando origem a inúmeros compostos com o objetivo de amenizar a instabilidade molecular, bem como diminuir a irritação cutânea.

Ao longo dos anos, mais de dois mil retinoides foram sintetizados, sendo tipicamente classificados em três gerações, com alguns segmentos reconhecendo uma quarta geração derivada dos piranones (KHALIL, BARDAWIL, et al., 2017).

A primeira geração de retinoides é composta por moléculas não aromáticas e que ocorrem naturalmente, sendo elas: retinol; retinal; isotretinoina; tretinoina (All-trans ácido retinoico) e a alitretinoina (9-cis ácido retinoico). A principal característica da primeira geração é de manter a estrutura cíclica da vitamina $\mathrm{A}$, alterando o grupo terminal polar e a cadeia poliênica (KHALIL, BARDAWIL, et al., 2017).

A segunda geração de retinoides é composta por moléculas monoaromáticas, alterando o anel cíclico da vitamina $\mathrm{A}$, tornando as estruturas mais lipofílicas aumentando a biodisponibilidade, nesta geração estão inclusos: etretinato; acetritina e motretinato (SORG, ANTILLE, et al., 2006).

A terceira geração tem como característica a seleção da atividade biológica, busca por efeitos adversos mínimos associados ao uso da vitamina A, de ação mais seletiva e de extensas modificações na molécula, formada pela ciclização, ou seja, colocação de anéis aromáticos na cadeia lateral poliênica, restringindo a flexibilidade da molécula. Neste grupo, temos: adapaleno; tazaroteno e bexaroteno, que são moléculas poliaromáticas. As estruturas rígidas permitem uma ligação mais específica aos receptores, quando comparadas com as moléculas dos retinoides de primeira geração (DINIZ, LIMA e ANTONIOSI FILHO, 2002; KHALIL, BARDAWIL, et al., 2017).

O uso da vitamina A em cosmecêuticos é amplamente discutido na literatura e muitos estudos apontam sua eficácia para o tratamento do envelhecimento cutâneo, acne e fotoenvelhecimento. E alguns de seus derivados mais utilizados cosmeticamente são: o retinol; o retinaldeído e os ésteres de retinil, nas formas de acetato, propinoato e ésteres de palmitato de retinil, respectivamente (FERNÁNDEZ e ARMARIO, 2003; DIEAMENT, COSTA e TORLONI, 2012).

Mesmo não sendo as formas ativas da vitamina A, a utilização desses derivados se justifica, visto que por meio da ação das enzimas presentes na epiderme, haverá ao final a conversão das formas inativas em ácido trans-retinoico, isômero ativo do ácido retinoico. Contudo, até que se ocorra a conversão, a eficácia do produto estará diretamente relacionada a questões técnicas como forma de apresentação, concentração; estabilidade da molécula e biológicas como a quantidade ideal de en- 


\section{Brazilian Journal of Natural Sciences | Versão On-line ISSN 2595 - 0584 \\ Edição no 1- vol. 1 - março 2018 | www.bjns.com.br}

zimas na pele para o efeito desejado e a capacidade dessas enzimas para a conversão da molécula em ácido trans-retinoico (DIEAMENT, COSTA e TORLONI, 2012).

A aplicação de retinoides em cosmecêuticos se baseia então na aplicação tópica de percursores de ácido retinoico que possuem maior tolerabilidade, e na participação das células epidérmicas que metabolizam esses percursores, tornando-os metabólitos ativos. De maneira resumida, pode-se fazer uma ordem de classificação quanto a atividade retinoide após a aplicação tópica e o nível de tolerância dos compostos utilizados. Referente a primeira ordem temos: ésteres de ácido retinóico > retinaldeído $>$ retinol $>>$ retinil, e para a segunda ordem: ésteres de retinil $>$ retinol $=$ retinaldeído $>>$ ácido retinoico (SORG, ANTILLE, et al., 2006).

Quanto mais próximo do ácido retinoico for a molécula, maior será sua atividade retinoidlike, em contrapartida o oposto ocorre em relação a tolerância que diminui (SORG, ANTILLE, et al., 2006).

\section{Retinol}

O retinol (all-trans-retinol) consiste da nomenclatura química utilizada para referir-se a forma alcoolica da molécula de vitamina A. Quimicamente, apresenta-se em forma de cristais amarelos ou sólido laranja, praticamente insolúvel em água, com fórmula molecular $\mathrm{C} 20 \mathrm{H} 30 \mathrm{O}$ e peso molecular $286.459 \mathrm{~g} / \mathrm{mol}$ (NIH, 2017a).

Estudos demonstram que o uso tópico de retinol, bem como de outros retinoides, promovem efeitos benéficos no tratamento de fotoenvelhecimento, reduzindo significativamente desde linhas de expressão superficiais até as mais profundas (BABAMIRI e NASSAB, 2010). Apresentando também, resultados significativos no tratamento da acne, diminuindo lesões acnéicas através de sua ação comedolítica e da diminuição da secreção excessiva de sebo pelas glândulas (VINHAL, ROBERTH, et al., 2014).

O retinol é utilizado em produtos dermatológicos e cosméticos desde o ano 1984, mas somente alguns anos depois, a sua aplicação no tratamento de fotoenvelhecimento e acne puderam ser comprovadas (MUKHERJEE, DATE, et al., 2006). Observou-se que sua ação é tão efetiva como a da tretinoina, com a vantagem de apresentar um nível baixo de irritação cutânea. Contudo, foi constatado que o retinol, apesar de se equiparar à tretinoina em resultados, possui ação 20 vezes menor do que a mesma (KANG, DUELL, et al., 1995).

De acordo com a ANVISA, por meio do Parecer Técnico $\mathrm{n}^{\circ}$ 04, de 21 de dezembro de 2010, da Câmara Técnica de Cosméticos, que dispõe sobre a utilização de retinoides em produtos cosméticos, o uso de retinol em formulações para fins de cosméticos é considerado seguro em concentrações de até $1 \%$. Acima desta concentração é considerado como medicamento, necessitando de prescrição médica para venda ou manipulação (ANVISA, 2010).

Figura 1: Molécula do retinol

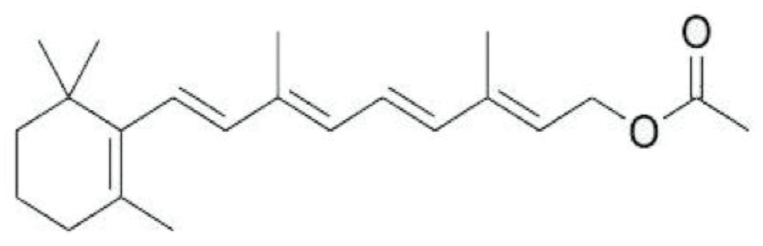

Fonte: Adaptado NIH, $2017^{3}$.

\section{Ácido retinoico}

$\mathrm{O}$ ácido retinoico (vitamina $\mathrm{A}$ ácida/ ácido all-trans retinoico), possui fórmula molecular $\mathrm{C} 20 \mathrm{H} 28 \mathrm{O} 2$, massa molar $300.4412 \mathrm{~g} / \mathrm{mol}$ e número de CAS 302-79-4. Disponível em várias formas isoméricas, destacam-se como as principais: alltrans, 9-cis e 13-cis (NIH, 2017).

Figura 2: Molécula do ácido retinoico<smiles>CC1=C(/C=C/C(C)=C/C=C/C(C)=C/C(=O)O)C(C)(C)CCC1</smiles>
Fonte: Adaptado NIH, $2017^{4}$. 


\section{Brazilian Journal of Natural Sciences | Versão On-line ISSN 2595 - 0584 \\ Edição no 1- vol. 1 - março 2018 | www.bjns.com.br}

${ }^{3}$ Disponível em: < https://pubchem.ncbi.nlm.nih.gov/compound/445354> Acesso em 12 de nov 2017.

${ }^{4}$ Disponível em: <https://pubchem.ncbi.nlm.nih.gov/compound/444795\#section=Top.> Acesso em: 12 de nov 2017.

Esta molécula é considerada um dos retinoides mais ativos, com larga aplicabilidade no tratamento de diversas doenças cutâneas, cujo efeito biológico está atribuído à atividade agonista junto aos receptores nucleares de ácido retinoico (RAR) e de retinoides $\mathrm{X}$ (RXR). Após a ligação do ácido retinoico com estes receptores há a formação de um heterodímero que interage com sequências de DNA localizadas em regiões promotoras de genes específicos, estas sequências são conhecidas como elementos de resposta ao ácido retinoico (RARE, do inglês responsive element retinoic acid), e a interação facilitada favorece a alteração dos padrões de expressão gênica, controlando a transcrição (SORG, ANTILLE, et al., 2006).

Para o tratamento tópico, o isômero (ácido alltrans retinoico) conhecido como tretinoina é o mais utilizado, em formulações: creme $(0,025 \%$, $0,05 \%, 0,1 \%$ e $0,4 \%)$; gel $(0,01 \%, 0,025 \%$ e $0,05 \%)$; soluções $(0,05 \%, 0,1 \%$ e $0,2 \%)$; loções $(0,1 \%)$; óleo $(0,05 \%)$ e compressas $(0,05 \%)$ (DIEAMENT, COSTA e TORLONI, 2012).

A tretinoina foi o primeiro retinoide de uso tópico aprovado pelo FDA (Food and Drug Administration) em 1971 (THIELITZ e GOLLNICK, 2008), sua molécula possui afinidade por todos os RAR (receptores do ácido retinoico), e especialmente com o RXR (retinoide $\mathrm{x}$ receptor) (IRBY, YENTZER e FELDMAN, 2008). Além disso, a tretinoina se liga a proteína II (CRABP II), proteína de ligação intracelular predominante na pele de ligação do ácido retinoico celular, esta ação tem sido proposta como a razão para o elevado potencial de irritação cutânea.

Este retinoide tem grande aplicabilidade para o tratamento de acne leve à moderada, envelhecimento cutâneo e fotoenvelhecimento. Sua molécula possui a capacidade de acelerar o chamado turnover celular, favorecendo a neocolagênese, de modo a adelgaçar o estrato córneo. É considerada ainda o padrão ouro para o tratamento tópico do fotoenvelhecimento, contudo, em cerca de 70 a $90 \%$ dos usuários causa ardor, eritema, xerose e descamação, o que limita o uso contínuo e ininterrupto (DIEAMENT, COSTA e TORLONI, 2012).

De modo geral, apesar da grande taxa de irritabilidade cutânea, a tretinoina é um dos princípios ativos mais utilizados em preparações tópicas dermatológicas sujeitas a prescrição, por favorecer a formação de colágeno na área onde a pele está lesada. A irritação cutânea, pode ser explicada, pelo menos em partes, por uma sobrecarga das vias ácido retinoico-dependentes com quantidades não fisiológicas de ácido retinoico exógeno na pele, irritando a pele circundante e causando um dos efeitos colaterais mais comuns e indesejados relacionados ao uso da tretinoina, a dermatite (SORG, ANTILLE, et al., 2006).

Geralmente a dermatite retinoide ocorre durante o primeiro mês de tratamento e tende a diminuir com o passar do tempo, respondendo a redução na frequência ou intensidade do uso do retinoide e a aplicação de hidratantes. Contudo, os estudos apontam que a utilização de concentrações inferiores as padronizadas para o ácido retinoico tópico, não garantem o sucesso terapêutico, pois, a entrega baixa do princípio ativo ocorre somente a partir de uma grande reserva epidérmica, ou seja, do estrato córneo para seus alvos intracelulares (SORG, ANTILLE, et al., 2006).

Para atender as necessidades de um mercado mais exigente, e particularmente as necessidades de pacientes com a pele sensível, muitas alterações foram realizadas na molécula de ácido retinoico para superar problemas de tolerabilidade e instabilidade da molécula (OBLONG e JARROLD, 2016).

A elucidação do complexo papel fisiológico na regulação dos padrões de expressão genética pelos retinoides, tornou possível a síntese de novas classes e compostos com diversas estruturas e efeitos biológicos, sempre baseada na interação com os receptores e sua conversão metabólica para ácido 
retinoico (OBLONG e JARROLD, 2016).

Em relação ao isômero ácido 9-cis-retinoico, que recebeu o nome de alitretinoina, trata-se de um pó amarelo com peso molecular é $300,44 \mathrm{~g} / \mathrm{mol}$, número de CAS 5300-03-8 e fórmula molecular de $\mathrm{C} 20 \mathrm{H} 28 \mathrm{O} 2$. É ligeiramente solúvel em etanol (7,01 $\mathrm{mg} / \mathrm{g}$ a $25^{\circ} \mathrm{C}$ ) e insolúvel em água (STIEFEL LABORATORIES INC., 1999). Em sua ação suprime a produção de quimiocinas que estão envolvidas no processo de transição de leucócitos para locais de inflamação da pele, reduz a expansão dos linfócitos $\mathrm{T}$ e as células apresentadoras de antígeno e inibe o efeito sobre a diferenciação celular. Os receptores de quimiocina CXCR3 (receptor de quimiocina CXC- 3) e as quimiocinas CCL20 (ligante de quimiocina (motivo C-C) 20), expressas em lesões cutâneas eczematosas, são reguladas por alitretinoina em queratinócitos estimulados por citocinas e células endoteliais dérmicas (STIEFEL LABORATORIES INC, 2016). Com esta finalidade, é utilizado em países europeus e da América do Norte, sob aprovação dos órgãos reguladores locais na forma tópica em concentração de $0,1 \%$, para lesões cutâneas em pacientes com sarcoma de Kaposi, relacionados ao HIV, com os benefícios clínicos de redução dos tamanhos das lesões, redução da taxa de progressão e melhora na qualidade de vida dos pacientes (LIGAND PHARMACEUTICALS INC., 1998; EUROPEAN MEDICINES AGENCY, 2010). É também utilizado na forma oral, comercializada em países como Reino Unido, na posologia de $10 \mathrm{mg}$ e $30 \mathrm{mg}$, com indicação de tratamento de adultos com eczema de mão crônico grave que não responde ao tratamento com potentes corticosteróides tópicos (STIEFEL LABORATORIES INC, 2016; STIEFEL LABORATORIES INC., 2017). Assim como outros retinoides apresentou níveis de teratogenicidade e seu uso é proibido em mulheres gestantes (STIEFEL LABORATORIES INC, 2016; LIGAND PHARMACEUTICALS INC., 1998).
Figura 3: Molécula da alitretinoina

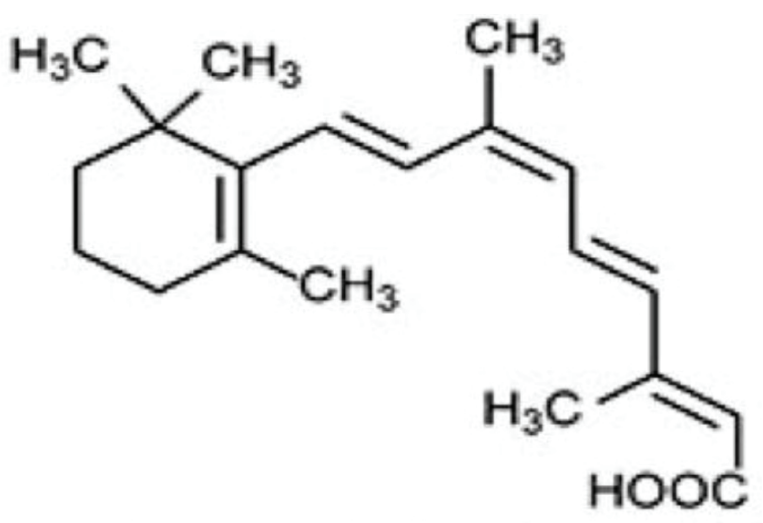

Fonte: Adaptado NIH, $2017^{5}$.

O uso do ácido retinoico é restrito por sua alta taxa de irritabilidade cutânea e instabilidade química, além disso, pela característica hidrofóbica da molécula, as formulações precisam dispor de emulsionantes e lipídios que melhorem sua solubilidade. Atualmente, há um grande investimento na criação de formulações de liberação controlada que utilizam micro encapsulamento, pois descobriu-se que quando disperso em cremes e emulsões, o ácido retinoico pode se tornar disponível imediatamente, sobrecarregando o tecido cutâneo e consequentemente ter maior potencial irritativo e de causar efeitos colaterais. Logo, é um grande desafio alcançar em uma mesma formulação uma elevada solubilidade e a liberação controlada (CASTLEBERRY, QUADIR, et al., 2017).

\section{Palmitato de retinol}

O palmitato de retinol (vitamina A palmitato/ retinol palmitato/ retinil palmitato), um éster do retinol, é a principal forma de vitamina A encontrada na epiderme durante o (NIH , 2017c) fórmula molecular C36H60O2, número de CAS 79-81-2 e sua massa molar é de 524,9 g/mol (NIH, 2017c; OLIVEIRA, DO PRADO, et al., 2014). 
Figura 4: Molécula do palmitato de retinol

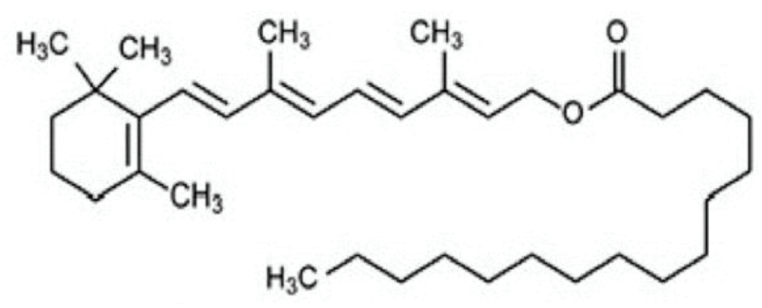

Fonte: Adaptado NIH, $2017^{6}$.

Por muito tempo foi utilizado como primeira opção nos tratamentos dermatológicos que visam o diminuir o efeito do envelhecimento na pele, pois possui maior estabilidade comparada à forma álcool e por isso causa menor irritabilidade à pele, se comparada ao seu antecessor. Para que seja ativado, de acordo com a necessidade biológica, o palmitato de retinol é convertido enzimaticamente pela esterases da pele para retinol pela clivagem da ligação éster e então é convertido em tretinoína (ácido all-trans-retinóico) por meio de processo de oxidação (SORG, ANTILLE, et al., 2006; OLIVEIRA, DO PRADO, et al., 2014).

Com relação ao perfil farmacológico ou toxicológico, não há diferenças qualitativas entre o palmitato de retinol e outros retinoides (WANG, DUSZA e LIM, 2010).

O palmitato de retinol mostrou-se o éster mais estável da vitamina A. Ele pode ser incorporado diretamente em emulsões e também pode ser colocado em gel quando um tensoativo for acrescentado para possibilitar a uniformidade da dispersão. O uso de antioxidantes são vantajosos na estabilidade química desse éster, sendo o atocoferol o mais recomendado. O palmitato de retinol também não deve ser exposto a temperaturas acima de $45^{\circ} \mathrm{C}$, para garantir sua estabilidade e recomendase que o produto cosmético que veicula o palmitato de retinol deve ter seu $\mathrm{pH}$ em torno de 5 a 6 , pois isso ajudará sua estabilidade da formulação. Mas, mesmo tomando todos esses cuidados, não é nada fácil conseguir estabilizar o palmitato de retinol em formulações cosméticas. Alguns pesquisadores sugerem que esse éster deve ser encapsulado em lipossomas, a fim de se conseguir melhorar a estabilidade (LEONARDI, 2005).

De acordo com o Parecer Técnico n ${ }^{\circ} 04$, de 21 de dezembro de 2010 da ANVISA, o uso de palmitato de retinol em formulações para fins de cosméticos é considerado seguro em concentrações entre 0,1 a $1,0 \%$ e deve ser utilizado em concentração máxima de 10.000 unidades internacionais - UI/g do produto acabado (sendo 1 Unidade Internacional (UI) de vitamina A corresponde a 0,55 $\mu \mathrm{g}$ do palmitato de retinol) (ANVISA, 2010).

Figura 5: Reações de intercambialidade entre o palmitato de retinol e outras formas da vitamina A.

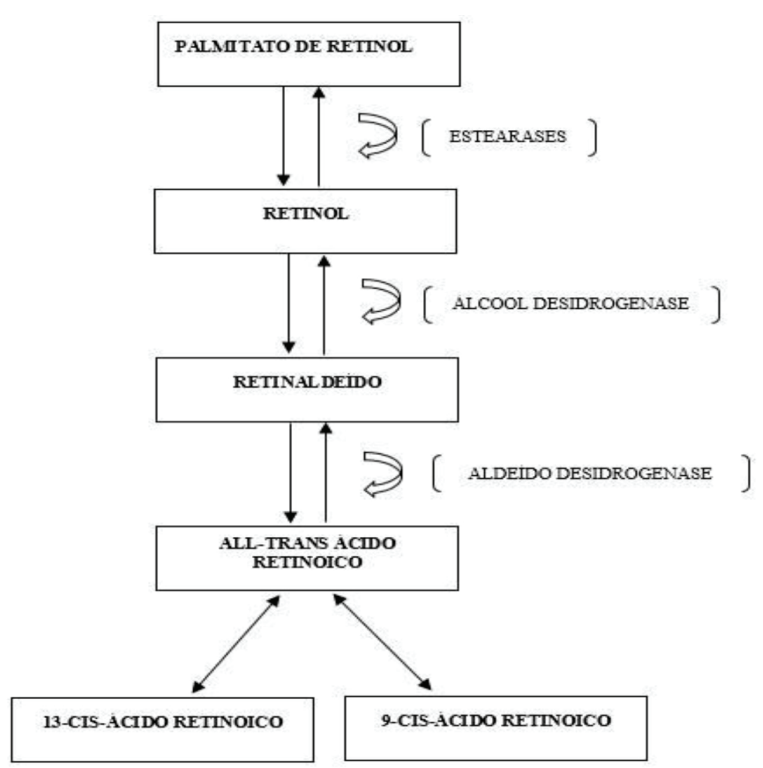

Fonte: Adaptado de Wang, Duzsda e Lim, 2010.

O retinaldeído (retinal; all-trans-retinal; retinaldehyde; vitamin A aldehyde), possui fórmula molecular C20H28O, número de CAS 116-31-4 e massa molar 284,443 g/mol (NIH, 2017d).

Em 1934, após 3 anos da determinação estrutural da molécula de vitamina A para os estudos com ações preventivas da doença xeroftalmia, por Karrer e seus colaboradores, Wald isolou uma substância que foi denominada retinida, haja vista ter sido retirada da retina de um animal. Entretanto, os estudos de Morton, em 1944, afirmam que essa

${ }^{6}$ Disponível em: < https://pubchem.ncbi.nlm.nih.gov/compound/5280531\#section=Top.> Acesso em: 12 de nov de 2017. 


\section{Brazilian Journal of Natural Sciences | Versão On-line ISSN 2595 - 0584 \\ Edição no 1- vol. 1 - março 2018 | www.bjns.com.br}

substância se tratava de um aldeído da vitamina $\mathrm{A}$, denominando-a retinaldeído ou retinal (DINIZ, LIMA e ANTONIOSI FILHO, 2002).

Figura 6: Molécula do retinaldeído<smiles>CC1=C(/C=C/C(C)=C/C=C/C(C)=C/C(=O)O)C(C)(C)CCC1</smiles>

Fonte: Adaptado NIH, $2017^{7}$.

Após a ação de algumas isoenzimas da álcool desidrogenase $(\mathrm{ADH})$, na qual a molécula de retinol é oxidada, obtemos o aldeído retinal, cuja característica na dermatologia é o rejuvenescimento, na qual apresenta boa tolerância na pele envelhecida. É o precursor natural do ácido retinoico com ação biológica e possui ações semelhantes às do ácido retinoico, mas com menor efeito irritante (SORG, KUENZLI, et al., 2005; ARRUDA, ARRUDA, et al., 2012). Isoenzimas de aldeído desidrogenase $(\mathrm{ALDH})$ e da retinal desidrogenase $(\mathrm{RDH})$ atuam sobre a molécula do aldeído da vitamina A, oxidando-a em ácido retinoico. O retinaldeído também é obtido pela conversão do betacaroteno no intestino (DINIZ, LIMA e ANTONIOSI FILHO, 2002).

Seu uso sobre o fotoenvelhecimento é dado devido sua ação no reparo do DNA, expressão de genes, estímulo ao crescimento e diferenciação de queratinócitos, melanócitos e fibroblastos, assim como produção da matriz extracelular pelos fibroblastos (BAGATIN, 2009).

Foram realizados estudos comparativos de retinaldeído a $0,05 \%, 0,05 \%$ de tretinoina e $0,05 \%$ de placebo, cujos resultados mostraram que o retinaldeído demonstrou uma melhora significativa nas rugas finas e profundas e apresentou menor ação irritativa do que a tretinoina (FERNÁNDEZ e ARMARIO, 2003).

Produtos cosmecêuticos contendo uma concentração de $0,05 \%$ a $1,0 \%$ de retinaldeído são per- mitidos, demonstrando eficácia, porém, menor do que a da tretinoina, que é o padrão-ouro do tratamento do fotoenvelhecimento nas concentrações de $0,025 \%, 0,05 \%$ e $0,1 \%$, que, por sua vez, não tem permissão para uso em cosmecêuticos devido sua característica irritativa (BAGATIN, 2009).

\section{Retinil acetato}

O retinil acetato (retinyl acetate ou acetato de retinil) é um derivado natural da vitamina A com aplicações em cosméticos. Possui fórmula molecular $\mathrm{C} 22 \mathrm{H} 32 \mathrm{O} 2$ e sua massa molar é de $328,5 \mathrm{~g} / \mathrm{mol}$ (NIH, 2017e).

A concentração máxima utilizada em loções corporais é de $0,05 \%$. É uma alternativa para formulações de produtos anti-idade por causar menos irritação e ser mais estável, porém sua performance é menor quando comparado à outros derivados retinoides (SCCS, 2016).

Figura 7: Molécula do retinil acetato<smiles>CC(=O)OC/C=C(C)/C=C/C=C(C)/C=C/C1=C(C)CCCC1(C)C</smiles>

Fonte: Adaptado NIH, $2017^{8}$.

\section{Tazaroteno}

O tazaroteno, que possui fórmula molécular C21H21NO2S, número de CAS 118292-40-3 e massa molar 351,464 g/mol (NIH, 2017f), é um retinoide de terceira geração lançado na metade da década de 90, derivado sintético da família dos retinoides acetilênicos (FERNÁNDEZ e ARMARIO, 2003; TAPIA, 1999). Ele possui uma estrutura poliaromática (Figura 8a) e suprime a expressão do receptor Toll-like, proteínas transmembrânicas do tipo I que formam uma parte do sistema imunológico inato; elas são uma via muito importan-

${ }^{7}$ Disponível em: < https://pubchem.ncbi.nlm.nih.gov/compound/5280531\#section=Top.> Acesso em: 12 de nov 2017.

${ }^{8}$ Disponível em: < https://pubchem.ncbi.nlm.nih.gov/compound/638034\#section=Top.> Acesso em: 12 de nov de 2017. 


\section{Brazilian Journal of Natural Sciences | Versão On-line ISSN 2595 - 0584 \\ Edição no 1- vol. 1 - março 2018 | www.bjns.com.br}

te ativada no processo de formação da acne. Essa supressão reduz a liberação de citocinas inflamatórias, óxido nítrico e inibe a inflamação celular, sendo uma ação benéfica no tratamento da acne (SORG, KUENZLI, et al., 2005). Dispõe de uma característica de rápida absorção pela pele após aplicação e, por ação das estearases, é imediatamente convertido em ácido tazarotênico (Figura $8 b)$, seu metabólito ativo que é menos irritante do que em sua forma de ácido livre (TAPIA, 1999; FERNÁNDEZ e ARMARIO, 2003).

Figura 8a: Molécula do tazaroteno

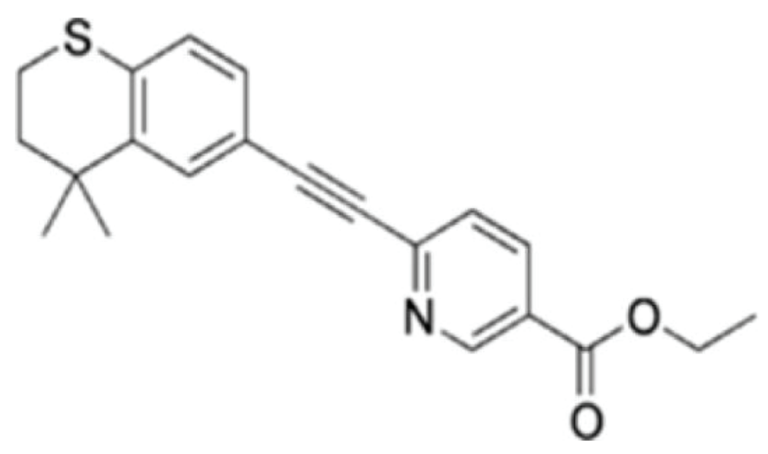

Fonte: Adaptado NIH, $2017^{9}$.

Figura 8b: Molécula do ácido tazarotênico

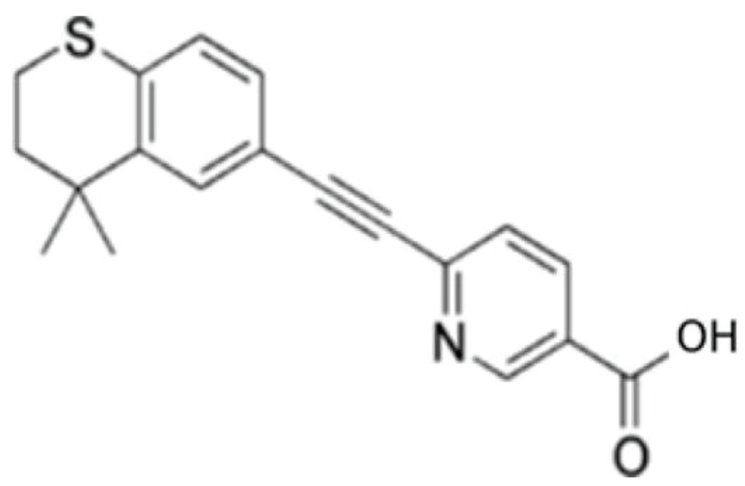

Fonte: Adaptado NIH, $2017^{10}$.

Apresenta afinidade e seletividade para com os receptores RAR- $\beta$ e RAR- $\gamma$ e, uma vez ligado a eles, ativa três genes indutores do tazaroteno, o TIG-1, TIG-2 e o TIG-3, sendo que o último possui efeito antiproliferativo celular (FERNÁNDEZ e
ARMARIO, 2003; SORG, KUENZLI, et al., 2005;).

Estudos realizados com essa substância mostraram resultados significativos no tratamento de acne e fotoenvelhecimento, além da redução com êxito dos sinais clínicos de psoríase, sendo considerado seguro e de tolerabilidade aceitável, em concentrações entre 0,1\% e 0,5\% (WOLF e JR., 2002; FERNÁNDEZ e ARMARIO, 2003; WEINSTEIN, KOO, et al., 2003). Em relação à acne, alguns estudos mostraram que é preferível sua apresentação em gel aquoso a $0,1 \%$, aplicado diariamente no período da noite, de 3-4 semanas, a fim de se obter uma diminuição das lesões da acne sem que ocorra possíveis efeitos adversos locais, pois seu maior aspecto desfavorável, e sua alta capacidade irritativa (FERNÁNDEZ e ARMARIO, 2003). O estudo que determinou sua melhor efetividade com o uso em veículo de gel, entre $0,05 \%$ e $0,01 \%$ em relação ao placebo, resultou em uma redução de números de comedões de $47 \%$ para a concentração de $0,05 \%$ e de $28 \%$ para a menor concentração, sendo que o placebo demonstrou redução de 19\%; dessa forma, sabe-se que os melhores resultados são obtidos frente a maior dosagem, porém, estes vêm com o maior risco de ocasionar efeitos adversos, o que levou ao abandono do estudo clínico. Dentre os eventos adversos observados durante os estudos encontram-se a descamação da pele, ardência e coceira no local da aplicação, além de secura, com variação de intensidade (FERNÁNDEZ e ARMARIO, 2003). Há outros estudos que sugerem o uso na apresentação em creme, alegando que em peles classificadas como normais e sensíveis, o creme demonstrou maior tolerabilidade e o uso do gel foi delegado ao adapaleno, de forma que foi considerado que a sensibilidade da pele da face tem muita influência na tolerabilidade do tratamento, de forma que é por ela que é definida a escolha da substância ativa a ser utilizada, sua concentração e apresentação (SORG, KUENZLI, et al., 2005).

Os estudos realizados mostraram que os cremes contendo uma concentração de $0,1 \%$ de tazaroteno é geralmente mais eficaz, embora a concen-

${ }^{9}$ Disponível em: < https://pubchem.ncbi.nlm.nih.gov/compound/5381\#section=Top. $>$ Acesso em: 12 de nov de 2017.

${ }^{10}$ Disponível em: < https://pubchem.ncbi.nlm.nih.gov/compound/147525\#section=Top. $>$ Acesso em 12 de nov de 2017. 


\section{Brazilian Journal of Natural Sciences | Versão On-line ISSN 2595 - 0584 \\ Edição no 1- vol. 1 - março 2018 | www.bjns.com.br}

tração de $0,5 \%$ seja bem mais tolerada, de forma que não demonstrou possuir ação sistêmica, ser mutagênico, carcinogênico e teratogênico, além de também não ser fototóxico ou fotossensibilizante (FERNÁNDEZ e ARMARIO, 2003; WEINSTEIN, KOO, et al., 2003; LEYDEN, STEIN-GOLD e WEISS, 2017). O creme com tazaroteno à $0,1 \%$ possui tolerabilidade comparável à tretinoina 0,025\% (LEYDEN, STEIN-GOLD e WEISS, 2017). Cremes com tazaroteno $0,1 \%$ mostraram, em 18 semanas de uso, uma significativa diminuição da intensidade da área da hiperpigmentação em comparação com o veículo $(\mathrm{P} \leq 0,05)$. Em comparação com o adapaleno, estudos realizados com 16 semanas de uso de ambas substâncias mostraram melhora significativa de hiperpigmentação pós -inflamatória (HPI) ocasionada pela acne com o uso de tazaroteno, sendo que $25 \%$ dos pacientes do estudo mostraram resultados de $100 \%$ da melhora da HPI; em contrapartida, o adapaleno não alcançou resultados consideráveis (LEYDEN, STEINGOLD e WEISS, 2017). Sua ação inibitória da formação de queratinócitos, percebida em cultivos humanos in vitro, ajuda a normalizar a hiperqueratinização na acne vulgaris e tem demonstrado efeitos anti-inflamatórios significantes nos testes experimentais (WOLF, 2002).

De modo a minimizar os eventos adversos com o uso do tazaroteno, mais especificamente as dermatites irritativas secundárias, associou-se corticoides de média e alta potência, que demonstraram que essa associação promove também uma maior eficácia e rapidez no aparecimento dos resultados clínicos, de forma que sua tolerabilidade em associação é maior quando utilizado em monoterapia (FERNÁNDEZ e ARMARIO, 2003).

Foi o primeiro retinoide tópico com uso aprovado para o tratamento de psoríase, de acordo com seu mecanismo de ação de forma seletiva aos receptores de ácido retinoico, que garantem uma normalização da diferenciação anormal dos queratinócitos e a redução da proliferação, além da diminuição da expressão dos marcadores da inflamação. Para a determinação desses resultados, foi necessária a realização de estudos moleculares com biopsias de lesões de psoríases e de peles ínte- gras, que demonstraram a atividade imunomodulatória da substância (WOLF, 2002; FERNÁNDEZ e ARMARIO, 2003). O uso de uma a duas vezes ao dia do gel aquoso com concentração entre $0,5 \%$ e $0,1 \%$ de tazaroteno resulta em reduções significativas dos sintomas clínicos da psoríase, sendo estes resultados advindo de estudos em concentrações de $0,01 \%, 0,5 \%$ e $0,1 \%$, além dos testes realizados com o gel sem a substância ativa, o placebo, na qual foi constatada uma melhora de 75\% (FERNÁNDEZ e ARMARIO, 2003).

Além disso, há alguns estudos isolados que sugerem um benefício do uso da substância como antienvelhecimento cutâneo e no tratamento de carcinomas basocelulares, neste caso com o uso do gel à $0,1 \%$, na qual obteve-se desaparecimento das lesões em $53 \%$ dos casos sem que houvesse recorrência e diminuição de $40 \%$ das lesões dos $47 \%$ dos casos restantes (FERNÁNDEZ e ARMARIO, 2003).

\section{Adapaleno}

O adapaleno é um retinoide de terceira geração, derivado sintético do ácido naftoico. Apresenta-se como um pó branco ou esbranquiçado, praticamente insolúvel em água, com fórmula molecular C28H28O3, número de CAS 106685-40-9 e peso molecular é 412,52 g/mol (NIH, 2017g; PISKIN e UZUNALI, 2007).

Surgiu a partir de alterações na molécula de ácido retinoico, com o intuito de resolver alguns problemas das gerações anteriores, dando origem a uma molécula com maior fotoestabilidade, menos irritante e com eficácia comparável a tretinoina (IRBY, YENTZER e FELDMAN, 2008).

Em um estudo comparativo, observou-se que o adapaleno possui uma estrutura química que oferece maior fotoestabilidade e resistência à oxidação. Em exposição à luz, 95\% da tretinoina foi degradada em um período de 24 horas, enquanto o adapaleno, não apresentou este grau de degradação mesmo em 72 horas de exposição (IRBY, YENTZER e FELDMAN, 2008).

A ação dos retinoides se dá através de ligação aos receptores: CRABR: receptor celular ligante do 


\section{Brazilian Journal of Natural Sciences | Versão On-line ISSN 2595 - 0584 \\ Edição no 1- vol. 1 - março 2018 | www.bjns.com.br}

ácido retinoico (cellular retinoic acid binding receptor), RARs: receptores do ácido retinoico (retinoic acid receptors), RXRs: receptores $\mathrm{x}$ retinoico (retinoid X receptores) (MILLIKAN, 2000; IRBY, YENTZER e FELDMAN, 2008).

A tretinoina possui afinidade por todos os subtipos de receptores RAR e CRABR, já o adapaleno possui seletividade pelos receptores do ácido retinoico (RAR) dos subtipos beta e gama. Essa seletividade confere ao adapaleno maior tolerabilidade e baixo risco de irritação da pele, podendo ser utilizado também em formulações com outros agentes tópicos como peróxido de benzoíla e antibióticos (MILLIKAN, 2000; LAYTON e EADY, 2009).

$\mathrm{O}$ adapaleno atua através da redução da comedogênese e modulação dos queratinócitos, conferindo propriedade comedolítica. Atua também no processo inflamatório, através da inibição da enzima lipoxigenase e pelo metabolismo de ácido araquidônico, porém, não possui ação contra a proliferação do agente Propionibacterium acnes (PISKIN e UZUNALI, 2007).

A concentração usual é de $0,1 \%$ a $0,3 \%$ em formulações à base de gel e de $0,1 \%$, em formulações à base de creme. Indica-se o uso no período noturno para evitar a exposição solar e possíveis irritações, como coceira, vermelhidão, descamação e queimação; devendo-se evitar o uso em gestantes devido a sua potencial indução de defeitos congênitos ao embrião (IRBY, YENTZER e FELDMAN, 2008).

Figura 9: Molécula do adapaleno

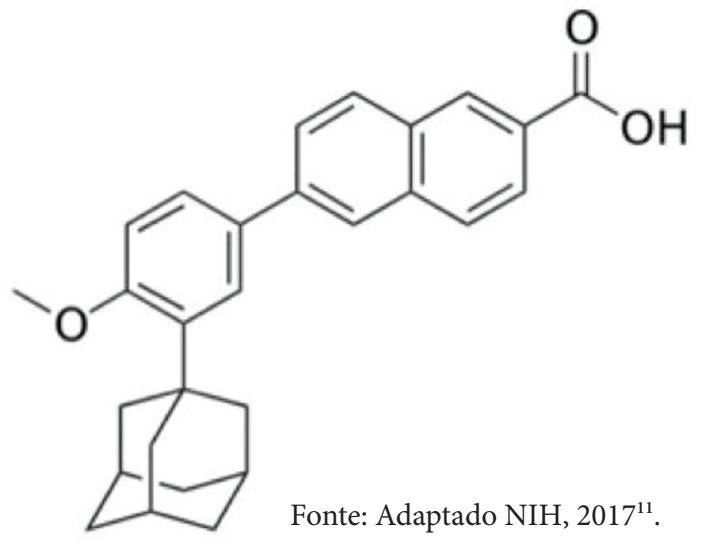

\section{Retinoato de hydroxipinacolona}

O éster retinoico (ou retinoato de hidroxypinacolona) é um éster de grau cosmético, derivado dos retinoides, e uma das mais recentes moléculas utilizadas. É um líquido levemente amarelado. Possui fórmula molecular $\mathrm{C} 26 \mathrm{H} 38 \mathrm{O} 3$ e sua massa molar é de 398,6 g/mol (GRANT INDUSTRIES, 2015).

Ele se liga diretamente aos receptores retinoides da pele, sem haver a necessidade de degradação metabólica. Este fato explica seu baixo potencial de irritação, visto que, embora largamente utilizados na Dermatologia, a irritação da pele, instabilidade fotoquímica e toxicidade limitam a utilização dos retinoides (GORMLEY, 2015).

Comparado aos outros derivados da vitamina A, esta nova molécula é a que apresenta menor irritação e descamação da pele, gerando maior adesão ao tratamento e menos inconvenientes ao paciente (GORMLEY, 2015; VERALDI; BARBARESCHI, et al., 2015).

$\mathrm{O}$ retinoato de hidroxypinacolona promove a renovação das células, melhorando o aspecto da pele, rejuvenescendo-a. Preenche rugas e linhas, clareia e uniformiza o tom da pele, prevenindo também o fotoenvelhecimento (NATUSENSE, 2016).

Estudos clínicos humanos comprovaram redução de linhas e rugas de expressão em pacientes após 14 dias de aplicação com o éster retinoico. Estudos comprovaram um perfil de irritação na pele menor quando comparado ao retinol, em um período de 24 horas. $100 \%$ dos participantes dos testes concordaram que o éster reduziu significativamente a flacidez e o ressecamento, proporcionou maciez e suavidade para a pele, melhorando sua aparência em geral, tonalidade, firmeza da pele e sensação de elasticidade. $80 \%$ dos participantes concordaram que o éster reduziu a aparência de linhas finas e rugas, diminui o aparecimento de manchas senis e melhorou a textura da pele em relação aos danos causados pelo sol (GORMLEY, 2015; NATUSENSE, 2016).

${ }^{11}$ Disponível em: < https://pubchem.ncbi.nlm.nih.gov/compound/60164\#section=Top.> Acesso em: 12 de nov de 2017. 
O éster retinoico é utilizado usualmente em concentrações entre $1 \%$ a $2 \%$, em emulsões, séruns, géis e sistemas anidros. Para favorecer a estabilização dos retinoides pode-se utilizar na formulação agentes antioxidantes, agentes quelantes, $\mathrm{pH}$ neutro e recipientes escuros e herméticos (GORMLEY, 2015; GRANT INDUSTRIES, 2015).
Figura 10: Molécula da retinoato de hydroxipinacolona

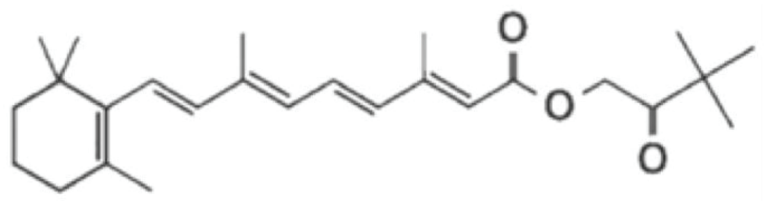

Fonte: Adaptado NIH, $2017^{12}$.

Tabela 1: Características dos principais retinoides comerciais de uso tópico

\begin{tabular}{|c|c|c|c|}
\hline Retinoide & $\begin{array}{l}\text { Fórmula } \\
\text { Molecular }\end{array}$ & Aplicação Usual & Concentração Usual \\
\hline Palmitato de retinol & $\mathrm{C}_{36} \mathrm{H}_{60} \mathrm{O}_{2}$ & $\begin{array}{l}\text { Uso cosmecêutico para envelhecimento } \\
\text { cronológico e fotoenvelhecimento }\end{array}$ & $\begin{array}{l}0,5 \text { a } 5 \%: \text { loções e } \\
\text { cremes }\end{array}$ \\
\hline Retinil Acetato & $\mathrm{C}_{22} \mathrm{H}_{32} \mathrm{O}_{2}$ & $\begin{array}{l}\text { Uso cosmecêutico para envelhecimento } \\
\text { cronológico e fotoenvelhecimento }\end{array}$ & 0,05\%: loções \\
\hline $\begin{array}{l}\text { Retinoato de hidro- } \\
\text { xypinacolona }\end{array}$ & $\mathrm{C}_{26} \mathrm{H}_{38} \mathrm{O}_{3}$ & $\begin{array}{l}\text { Uso cosmecêutico para envelhecimento } \\
\text { cronológico e fotoenvelhecimento }\end{array}$ & $\begin{array}{l}1,0 \text { a } 2,0 \% \text { : emulsões, } \\
\text { séruns, géis e } \\
\text { sistemas anidros. }\end{array}$ \\
\hline Retinol & $\mathrm{C}_{20} \mathrm{H}_{30} \mathrm{O}$ & $\begin{array}{l}\text { Tratamento de acne vulgar, } \\
\text { envelhecimento cronológico e } \\
\text { fotoenvelhecimento }\end{array}$ & 0,01 a $0,4 \%$ : creme \\
\hline Retinaldeído & $\mathrm{C}_{20} \mathrm{H}_{28} \mathrm{O}$ & $\begin{array}{l}\text { Uso cosmecêutico para envelhecimento } \\
\text { cronológico e fotoenvelhecimento }\end{array}$ & $\begin{array}{l}\text { 0,05\%: cremes, géis } \\
\text { e loções }\end{array}$ \\
\hline Tretinoína & $\mathrm{C}_{20} \mathrm{H}_{28} \mathrm{O}_{2}$ & $\begin{array}{l}\text { Tramentos dermatológicos de Acne } \\
\text { leve a moderada; Envelhecimento } \\
\text { cronológico e fotoenvelhecimento }\end{array}$ & $\begin{array}{l}\text { 0,025\%, 0,05\%, 0,1 e } \\
\text { 0,4\%: creme } \\
\text { 0,01\%, 0,025\% e } \\
\text { 0,05\%: gel } \\
\text { 0,05\%, 0,1\% e 0,2\%: } \\
\text { solução } \\
\text { 0,1\%: loção } \\
\text { 0,05\%: óleo } \\
\text { 0,05\%: compressa }\end{array}$ \\
\hline Alitretinoína & $\mathrm{C}_{20} \mathrm{H}_{28} \mathrm{O}_{2}$ & $\begin{array}{l}\text { Tratamento de lesões cutâneas em } \\
\text { sarcomas de Kaposi, relacionados ao } \\
\text { HIV e eczema de mão crônico grave }\end{array}$ & $0.1 \%$ gel \\
\hline Adapaleno & $\mathrm{C}_{28} \mathrm{H}_{28} \mathrm{O}_{3}$ & $\begin{array}{l}\text { Tratamento dermatológico de } \\
\text { Acne leve a moderada e psoríase. } \\
\text { Demonstrou possibilidade de uso para } \\
\text { fotoenvelhecimento }\end{array}$ & 0,1 e 0,3\%: gel \\
\hline Tazaroteno & $\mathrm{C}_{21} \mathrm{H}_{21} \mathrm{NO}_{2} \mathrm{~S}$ & $\begin{array}{l}\text { Tratamento dermatológico de } \\
\text { acne leve a moderada e psoríase. } \\
\text { Demonstrou possibilidade de uso para } \\
\text { fotoenvelhecimento e carcinomas } \\
\text { basocelulares. }\end{array}$ & $\begin{array}{l}0,01,0,05,0,1 \text { e } \\
0,5 \%: \text { gel e creme. }\end{array}$ \\
\hline
\end{tabular}

Fonte: Adaptado de Dieament, Costa, Torloni (2012, p.311).

${ }^{12}$ Disponível em: < https://pubchem.ncbi.nlm.nih.gov/compound/25054592\#section=Top.> Acesso em: 12 de nov de 2017. 
Tecnologia de encapsulação do ativo e novas associações

As ciclodextrinas (oligossacarídeos cíclicos), os lipossomas e as nanosferas ou nanopartículas (estruturas coloidais, constituídas por vesículas de um fino invólucro de polímero biodegradável e uma cavidade central com núcleo oleoso, no qual a substância ativa está dissolvida) são veículos para liberação dos princípios ativos. Essa tecnologia diminui os efeitos adversos do retinol, pois a encapsulação do ativo diminui a penetração e aumenta o armazenamento das moléculas nas primeiras camadas da epiderme, garantindo um aumento prolongado através de sua liberação progressiva. Além de diminuir o problema de instabilidade, pois evita o contato com o oxigênio, luz e com o hidrogênio livre de formulações com baixos pH's (VANZIN; CAMARGO, 2015).

As membranas do ativo são sensíveis a diversas proteases, não havendo nenhuma atividade proteolítica específica requerida para digerir as membranas das microcápsulas e liberar o composto ativo encapsulado. Essa digestão lenta da membrana conduz a uma liberação lenta do material encapsulado, para melhor biodisponibilidade e eficácia e um uso mais suave de compostos cosméticos ativos mal tolerados, caso do retinol. Em adição a uma biocompatibilidade otimizada, a encapsulação de moléculas irritantes, apresenta penetração reduzida na pele e, desta forma, o fenômeno de intolerância resultante da citotoxicidade é reduzido (SOUZA; ANTUNES JUNIOR, 2016).

Para aumentar a eficácia na utilização dos retinoides com menor irritação cutânea, também estão sendo desenvolvidas formulações que utilizam retinoides associados à ativos ácidos, como: éster de retinol com ácido salicílico (DRAELOS, LEWIS, et al., 2015) e retinol com ácido tetra-hidro-jasmônico (LR2412) (BOULOC, VERGNANINI e ISSA, 2015).

\section{Considerações finais}

Ao longo dos anos a aplicação da vitamina A e dos retinoides na área dermatológica expandiu de forma significativa, saindo do contexto exclusivo médico, chegando até as prateleiras através dos produtos denominados cosmecêuticos, que ainda aguardam as considerações dos órgãos regulatórios. A pesquisa e desenvolvimento de novas moléculas, por sua vez, precisarão se adaptar às demandas do mercado, das quais podemos destacar, entre as mais recentes, o grande investimento em pesquisas com nanotecnologia, alteração de grupos funcionais e sintetização laboratorial de moléculas retinoides-like, ou seja, que atuam como retinoides.

A nanotecnologia vem sendo uma grande aliada para a utilização dos retinoides, com a aplicação de nanoesferas, que diminuem os efeitos adversos indesejáveis, uma vez que controlam a penetração do ativo e aumentam o armazenamento das moléculas nas primeiras camadas da epiderme, garantindo uma liberação progressiva.

Dentre os derivados da vitamina A empregados nos cosmecêuticos, a mais recente molécula desenvolvida foi o estér retinoato de hidroxypinacolona, que apresenta menor irritação e descamação da pele, menor instabilidade fotoquímica e toxicidade, quando comparado aos outros retinoides. Contudo, apesar dos avanços, os retinoides continuam foto instáveis, com potencial teratogênico e irritativo para a pele, não sendo, portanto, substâncias totalmente seguras para o uso. Com o crescimento do mercado dermocosméticos inúmeras pesquisas são esperadas para que essas contraindicações diminuam ou mesmo desapareçam.

\section{Referências bibliográficas}

ANVISA. Agência Nacional de Vigilância Sanitária. Parecer Técnico n ${ }^{\circ}$ 04, de 21 de dezembro de 2010. Dispõe sobre a utilização de retinoides em produtos cosméticos (Revisão do Parecer Técnico CATEC $\mathrm{n}^{\circ} 03$, de 22 de dezembro de 2002). Brasília, DF, 21 de dezembro de 2010.

ARRUDA, L. et al. Avaliação de dermocosmético com retinaldeído, nicotinamida e vitis vinifera no fotoenvelhecimento cutâneo de mulheres entre 25 e 40 anos de idade. Surgical And Cosmetic Dermatology, v. 4, n. 1, p. 38-44, Março 2012. 


\section{Brazilian Journal of Natural Sciences | Versão On-line ISSN 2595 - 0584 \\ Edição no 1- vol. 1 - março 2018 | www.bjns.com.br}

BABAMIRI, K.; NASSAB, R. Cosmeceuticals: The Evidence Behind the Retinoids. Aesthetic Surgery Journal, v. 30, n. 1, p. 74-77, Janeiro 2010.

BAGATIN, E. Mecanismos do envelhecimento cutâneo e o papel dos cosmecêuticos. Revista Brasileira de Medicina (Rio de Janeiro), v. 66, n. supl.3, p. 5-11, Abril 2009. Disponivel em: <http://www. moreirajr.com.br/revistas.asp?fase $=$ r003\&id_materia $=3997>$.

BARROS, B. S.; ZAENGLEIN, A. L. The Use of Cosmeceuticals in Acne: Help or Hoax? Am J Clin Dermatol, v. 18, n. 2, p. 159-163, 06 Jan 2017.

BRASIL. Agência Nacional de Vigilância Sanitária. Resolução RDC no 07, de 10 de fevereiro de 2015. Dispõe sobre os requisitos técnicos para a regularização de produtos de higiene pessoal, cosméticos e perfumes e dá outras providências. Diário Oficial da União. Brasília, DF, 11 de fevereiro de 2015. BOULOC, A.; VERGNANINI, A. L.; ISSA, M. C. A double-blind randomized study comparing the association of Retinol and LR2412 with tretinoin $0.025 \%$ in photoaged skin. Journal of Cosmetic Dermatology, v. 14, n. 1, p. 40-46, Mar 2015.

CAETANO, J. P. S. Aspectos Reguladores dos Cosmecêuticos. In: COSTA, A. Tratado Internacional de Cosmecêuticos/Adilson Costa. Rio de Janeiro: Guanabara Koogan, 2012. p. 14-19.

CASTLEBERRY, et al. Polymer conjugated retinoids for controlled transdermal delivery. Journal of Controlled Release, v. 262, p. 1-9, Set 2017. ISSN ISSN 0168-3659.

COSTA, A. O Conceito de Cosmecêutico. In: COSTA, A. Tratado Internacional de Cosmecêuticos/Adilson Costa. Rio de Janeiro: Guanabara Koogan, 2012. p. 4-6.

DIEAMENT, G. D. C.; COSTA, A.; TORLONI, L.

B. D. O. Retinoides. In: COSTA, A. Tratado Internacional de Cosmecêuticos. Rio de Janeiro: Guanabara Koogan, 2012. p. 307-314.

DINIZ, G. A.; LIMA, M.; ANTONIOSI FILHO, N. R. Isotretinoína: perfis farmacológico, farmacocinético e analítico. Rev. Bras. Cienc. Farm., v. 38, n. 4, p. 415-430, Dezembro 2002.

DRAELOS, Z. et al. Novel retinoid ester in combination with salicylic acid for the treatment of acne. Journal of Cosmetic Dermatology, v. 15, n. 1, p. 36-
42, Out 2015.

EUROPEAN MEDICINES AGENCY. Panretin: alitretinoin. European Medicines Agency, Science Medicines Health, Londres, 2010. Disponível em: $<$ http://www.ema.europa.eu/docs/en_GB/document_library/EPAR_-_Summary_for_the_public/ human/000279/WC500038705.pdf>. Acesso em: 26 set. 2017.

FAVARO DE ARRUDA, H. et al. Assessment of dermocosmetics containing retinaldehyde, nicotinamide and Vitis vinifera in the cutaneous photoaging. Surgical \& Cosmetic Dermatology, p. 38-44, 2012.

FERNÁNDEZ, J. M. V.; ARMARIO, J. C. H. Retinoides en dermatología. Medicina Cutanea Ibero -Latino-Americana, v. 31(5), p. 271-294, 2003.

GRANT INDUSTRIES. Granactive Retinoid: The Power of Retinol without the Irritation. Cosmetics \& Toiletries. 2015. Disponível em: <http://www. cosmeticsand toiletries.com/formulating/function/active/Granactive-Retinoid-The-Power-of -Retinol-without-the-Irritation-292396371.html> Acesso em: 12/11/2017

GORMLEY, John. Granactive Retinoid: The Power of Retinol without the Irritation. In-cosmetics. 2015. Disponível em:<http://www.in-cosmetics. com/RXUK/RXUK_InCosmetics/2015-Website/ Documents/in-cos15,\%20IS, \%20T2,D1,Granactive $\% 20$ Retinoid\%20The\%20power\%20of\%20 retinol\%20without\%20the\%20irritation,John\%20 Gormley.pdf?v=635653937948561840> Acesso em: 12/11/2017.

IRBY, C. E.; YENTZER, B. A.; FELDMAN, S. R. A Review of Adapalene in the Treatment of Acne Vulgaris. Journal of Adolescent Health, v. 43, n. 5, p. 421-424, 2008.

KANG, S. et al. Application of retinol to human skin in vivo induces epidermal hyperplasia and cellular retinoid binding proteins characteristic of retinoic acid but without measurable retinoic acid levels or irritation. The Journal Investigative Dermatology, v. 105, n. 4, p. 549-556, Outubro 1995.

KHALIL, S. et al. Retinoids: A Journey from the Molecular Structures and Mechanisms of Action to Clinical Uses in Dermatology and Adverse Ef- 


\section{Brazilian Journal of Natural Sciences | Versão On-line ISSN 2595 - 0584 \\ Edição no 1- vol. 1 - março 2018 | www.bjns.com.br}

fects. Journal of Dermatological Treatment, v. 19, n. 32, Março 2017.

KLIGMAN, A. M. The growing importance of topical retinoids in clinical dermatology: a retrospective and prospective analysis. Journal of the American Academy of Dermatology, v. 39, Agosto 1998.

LAYTON, A. M.; EADY, E. A. Benzoil peroxide and adapalene fixed combination: a novel agent for acne. British Journal of Dermatology, v. 161, n. 3, p. 971-976, 2009.

LEONARDI, G. R. Cap.6 - Importantes substâncias ativas usadas na Cosmetologia. In:

LEONARDI, G.R. Cosmetologia Aplicada. $1^{\text {a }}$ Ed. São Paulo: Editora Medfarma, 2005, p.87

LEYDEN, J.; STEIN-GOLD, L.; WEISS, J. Why Topical Retinoids Are Mainstay of Therapy. Dermatol Ther (Heidelb), Abril 2017.

LIGAND PHARMACEUTICALS INC. Pharmacology review, Panretin gel 0,1\% 9-cis-retinoic acid. U.S. Food and Administration, Industry Systems, 1998. Disponível em: <https://www.accessdata.fda.gov/drugsatfda_docs/nda/99/20886_phrmr_P1.pdf >. Acesso em: 26 set. 2017.

MANELA-AZULAY, M.; BAGATIN, E. Cosmeceuticals vitamins. Clinics in Dermatology, p. 469-474, 2009.

MILLIKAN, L. E. Adapalene: an update on newer comparative studies between the various retinoids. International Journal of Dermatology, v. 39, n. 10, p. 784-788, 2000.

MUKHERJEE, et al. Retinoids in the treatment of skin aging: an overview of clinical efficacy and safety. Clinical Interventions in Aging, v. I, n. 4, p. 327-348, 2006.

NATUSENSE. Granactive Retinoid: O Retinoide Inovador sem irritação. Pharmapele. 2016. Disponível em: <https://www.pharmapele.com.br/repositorio/pdf/literatura-medica.pdf $>$ Acesso em: 12/11/2017.

NIH. National Institute of Health (Estados Unidos). Nacional Library of Medicine. National Center for Biotechnology Information. Compound Summary for CID 445354. Retinol. PubChem Compound Database. Disponível em: $<$ https:// pubchem.ncbi.nlm.nih.gov/compound/445354\#- section $=$ Chemical-and-Physical-Properties $>$. Acesso em: 12 nov. 2017a.

Compound Summary for CID 444795.

Retinoic Acid. PubChem Compound Database. Disponível em:<https://pubchem.ncbi.nlm. nih.gov/compound/444795>. Acesso em: 26 set. $2017 \mathrm{~b}$.

Compound Summary for CID 5280531. Vitamin A Palmitate. PubChem Compound Database. Disponível em:<https://pubchem.ncbi.nlm. nih.gov/compound/retinyl_palmitate\#section=Top >. Acesso em: 26 set. 2017c.

Compound Summary for CID 638015.

Retinal. PubChem Compound Database. Disponível em:< https://pubchem.ncbi.nlm.nih.gov/compound/638015> Acesso em: 12 set. 2017d.

Compound Summary for CID 638034.

Retinyl Acetate. PubChem Compound Database. Disponível em:<https://pubchem.ncbi.nlm.nih. gov/compound/638034\#section=Top $>$ Acesso em: 12 set. $2017 \mathrm{e}$.

.Compound Summary for CID 5381. Tazarotene. PubChem Compound Database. Disponível em: < https://pubchem.ncbi.nlm.nih.gov/compound/5381> Acesso em: 12 set. $2017 \mathrm{f}$.

.Compound Summary for CID 60164. Adapalene. PubChem Compound Database. Disponível em:< https://pubchem.ncbi.nlm.nih.gov/ compound/60164> Acesso em: 12 set. 2017g.

OBLONG, J. E.; JARROLD, B. B. Retinoides. In:_ . DRAELOS, Z. D. Cosmecêuticos/ editado por Zoe Diana Draelos. Tradução de Luiz Euclydes Trindade Frazão Filho e Marcela De Melo Silva. 3a. ed. Rio de Janeiro: Elsevier, 2016. Cap. 4, p. 33-35.

OLIVEIRA, M. B. et al. Topical Application of Retinyl Palmitate-Loaded Nanotechnology-Based Drug Delivery Systems for the Treatment of Skin Aging. BioMed Research International, v. 2014, p. 7, Março 2014. ID 632570.

PISKIN, S.; UZUNALI, E. A review of the use of adapalene for the treatment of acne vulgaris. Therapeutics and clinical risk management, v. 3, n. 4 , p. 621-624, 2007.

SCCS. Scientific Committee on Consumer Safety. Opinion on Vitamin A (Retinol, Retinyl Acetate, 
Retinyl Palmitate). Luxemburgo. 2016.

SORG, O. et al. Proposed mechanisms of action for retinoid derivatives in the treatment of skin aging. Journal of Cosmetic Dermatology, v. 4, p. 237-244, 2005.

SORG, O. et al. Retinoids in cosmeceuticals. Dermatologic Therapy, v. 19, p. 289 -296, 2006.

SOUZA, V. M.; ANTUNES JUNIOR, D., Ativos Dermatológicos: dermocosméticos e nutracêuticos. São Paulo: Daniel Antunes Junior. v.9, p. 471472. 2016.

STIEFEL LABORATORIES INC. Panretin“ (alitretinoin) gel $0.1 \%$ (For topical use only). U.S. Food and Administration, Industry Systems, 1999. Disponível em: <https://www.accessdata.fda.gov/ drugsatfda_docs/label/1999/20886lbl.pdf>. Acesso em: 28 set. 2017.

. Prescribing Information: TOCTINO (alitretinoin) 10mg or 30mg capsules. GlaxoSmithKline (GSK), 2016. Disponível em: <https://hcp. gsk.co.uk/content/dam/global/hcpportal/en_GB/ products/toctino/documents/Toctino PI July 2016.pdf>. Acesso em: 26 set. 2017.

Toctino $10 \mathrm{mg}$ and $30 \mathrm{mg}$ soft capsules. Electronic Medicines Compendium (eMC), 2017. Disponível em: <http://www.medicines.org.uk/ $\mathrm{emc} /$ medicine $/ 21177 / \mathrm{SPC} /$ Toctino $+10 \mathrm{mg}+\mathrm{an}-$ d+30mg+soft+capsules/>. Acesso em: 28 set. 2017. TAPIA, A. G. Tazarotene: a new topical retinoid. Actas Dermosifiliograficas, v. 90, n. 3, p. 71-78, 1999.

THIELITZ, A.; GOLLNICK, H. Topical Retinoids in Acne Vulgaris. Am J Clin Dermatol, v. 9, n. 6, p. 369-381, 2008.

VANZIN, S. B.; CAMARGO, C. P., Entendendo Cosmecêuticos: Diagnósticos e Tratamentos. São Paulo: Livraria Santos, v.2, 2. ed., p. 43-47, 2015. VERALDI, S. et al. Treatment of mild to moderate acne with a fixed combination of hydroxypinacolone retinoate, retinol glycospheres and papain glycospheres. Giornale Italiano di Dermatologia e Venereologia, v. 150, n. 2, p. 143-147, Abril 2015. VINHAL, D. C. et al. Terapia Retinóide na Acne Vulgar. Revista Eletrônica de Farmácia, v. XI, n. 3, p. 80-101, 2014.

WANG, S. Q.; DUSZA, S. W.; LIM, H. W. Safety of retinyl palmitate in sunscreens: A critical analysis. Journal of the American Academy of Dermatology, v. 63, n. 3, Novembro 2010.

WEINSTEIN, G. D. et al. Tazarotene cream in the treatment of psoriasis: Two multicenter, double -blind, randomized, vehicle-controlled studies of the safety and efficacy of tazarotene creams $0.05 \%$ and $0.1 \%$ applied once daily for 12 weeks. Journal of the American Academy of Dermatology, v. 48, n. 5, Maio 2003.

WOLF, J. E. Potential anti-inflammatory effects of topical retinoids and retinoid analogues. Advances In Therapy, Houston, Texas, v. 19, n. 3, p.109-118, maio 2002. 